DOI: https://doi.org/10.15688/re.volsu.2019.1.10

UDC 338

Submitted: 25.12.2018

LBC 65.05

Accepted: 29.01.2019

\title{
ASSESSMENT OF INVESTMENT RESOURCES OF THE REGION IN THE STRATEGIC CONTEXT
}

\author{
Svetlana V. Gerasimova \\ Crimean Federal University named after V. I. Vernadsky, Simferopol, Russian Federation \\ Lyudmila M. Borshch \\ Crimean Federal University named after V. I. Vernadsky, Simferopol, Russian Federation
}

\begin{abstract}
The article analyzes the theory and practice of strategic planning, since increasing the welfare of the region is directly dependent on investments in the means of production, infrastructure development and technological development, and investments are needed for these purposes. The effectiveness of the implementation of the regional development strategy is provided by the comprehensiveness of the measures that form the investment environment, which can provide a certain socio-economic effect for the region, while increasing its competitiveness.

With this aim, an important methodological task of choosing methods and tools for analyzing and evaluating the use of investment resources is determined. An assessment of strategic planning in the region was made on the example of the Republic of Crimea (hereinafter referred to as the region) on the formation of an attractive investment climate. Positive and negative factors of development of investment activity for the formation of a favorable investment climate have been identified. Investment indicators are used to more fully substantiate and comprehensively characterize the state of regional investments. All indicators correspond to a consistent system, determine the interconnectedness and interdependence of the development of investment activities. An assessment of investment activity in the region was carried out using an indicative method for estimating values by groups of indicators, followed by a comparison of the actual values of the indicators to assess the effectiveness of investment activities in the region. The dynamics of integral indicators in investment activity, investment resources are determined; investments in fixed capital are also analyzed for three groups of indicators: investment climate, investment resource potential, investment efficiency of the resources used. From the point of view of practical applications, the indicative assessment method helps to identify weak points in the formation of a favorable investment climate and eliminate the imbalances. A functioning system of analysis with the use of a project management system makes it possible to shorten the time needed for the approval of investment projects, to increase the efficiency of resource and time use.

Key words: region, offensive globalization, investments, strategic planning, indicative method, investment climate, reflection of economic thought, free economic zone, integral indicators.

Citation. Gerasimova S.V., Borsch M.L. Assessment of Investment Resources of the Region in the Strategic Context. Regionalnaya ekonomika. Yug Rossii [Regional Economy. The South of Russia], 2019, vol. 7, no. 1, pp. 112-123. (in Russian). DOI: https://doi.org/10.15688/re.volsu.2019.1.10
\end{abstract}

УДК 338

Дата поступления статьи: 25.12.2018

ББК 65.05

Дата принятия статьи: 29.01.2019

\section{ОЦЕНКА ИНВЕСТИЦИОННЫХ РЕСУРСОВ РЕГИОНА В СТРАТЕГИЧЕСКОМ КОНТЕКСТЕ}

\author{
Светлана Васильевна Герасимова
}

Крымский федеральный университет им. В.И. Вернадского, г. Симферополь, Российская Федерация

(C) Герасимова С.В., Борщ Л.М., 2019 


\section{Людмила Михайловна Борщ}

Крымский федеральный университет им. В.И. Вернадского, г. Симферополь, Российская Федерация

Аннотация. В статье проведен анализ теории и практики стратегического планирования, поскольку наращивание благосостояния региона напрямую зависят от инвестиций в средства производства, развитие инфраструктуры и технологического развития, для этих целей необходимы инвестиционные ресурсы. Эффективность реализации стратегии регионального развития обеспечивается комплексностью мер, формирующих инвестиционную среду, которая сможет обеспечить определенный социально-экономический эффект для региона, повышая при этом его конкурентоспособность.

В статье определяется важная методологическая задача выбора методов и инструментов проведения анализа и оценки использования инвестиционных ресурсов. Произведена оценка стратегического планирования в регионе на примере Республики Крым (далее - регион) по формированию привлекательного инвестиционного климата. Определены положительные и отрицательные факторы развития инвестиционной деятельности для формирования благоприятного инвестиционного климата. Применены инвестиционные индикаторы для более полного обоснования и всесторонней характеристики состояния региональных инвестиций. Все показатели соответствуют последовательной системности, определяют взаимосвязанность и взаимозависимость развития инвестиционной деятельности. Проведена оценка инвестиционной деятельности в регионе при помощи индикативного метода оценки величин по группам показателей с последующим сопоставлением фактических значений индикаторов для оценки эффективности инвестиционной деятельности в регионе. Определена динамика интегральных показателей в инвестиционной деятельности, инвестиционных ресурсах, также проанализированы инвестиции в основной капитал по трем группам показателей: инвестиционный климат, инвестиционный ресурсный потенциал, инвестиционная эффективность использованных ресурсов. С точки зрения практических применений, индикативный метод оценки способствует выявлению слабых мест в формировании благоприятного инвестиционного климата и устранению выявленных диспропорций. Функционирующая система анализа с применением системы проектного управления позволяет сократить сроки согласования инвестиционных проектов, повысить эффективность использования ресурсов и времени.

Ключевые слова: регион, наступательная глобализация, инвестиции, стратегическое планирование, индикативный метод, инвестиционный климат, рефлексия экономической мысли, свободно-экономическая зона, интегральные показатели.

Цитирование. Герасимова С. В., Борщ Л. М. Оценка инвестиционных ресурсов региона в стратегическом контексте // Региональная экономика. Юг России. 2019. Т. 7, № 1. С. 112-123. DOI: https://doi.org/10.15688/ re.volsu.2019.1.10

\section{Постановка проблемы}

Стратегическое планирование до настоящего времени является недостаточно изученной темой в отечественной науке. Это обусловлено эволюцией ускоренных процессов рыночной трансформации экономики, усиленным влиянием внешних факторов, к которым не успевали адаптироваться бизнес, общество и государственное управление. Следует отметить, что технологическая эволюция выражается в ускорении наступательной глобализации мирового господства и не оставляет времени для медленного реформирования экономики. На глобальные вызовы следует реагировать своевременно и работать на опережение, как это свойственно развитым странам. Безусловно, такое поведение государства может сформироваться при условии системы государственного и корпоративного стратегического планирования с соответствующим институциональным обеспечением, готовности органов государственной власти, регионов, бизнес структур к восприятию и реализации стратегического планирования.

Сложный и неизвестный по своему масштабу переход государства к организации общественных отношений на рыночных основах требует рефлексии научной экономической мысли относительно выбора новой парадигмы, которая сможет найти объяснение сущности организационно-экономического механизма этих технологических преобразований, формируя новые положения относительно инструментов обеспечения эффективности таких преобразований.

В России проблематика и анализ практики стратегического планирования берет свои истоки в работах профессионалов стратегического планирования на уровне территориального развития [Анимица, 2005; Жихаревич, Прибышин, 2013; Селиверстов, 2013; Швецов, Демьяненко, Украинский, 2016], макроэкономическое моделирование, прогнозирование и планирование регионального развития характеризуются в трудах В.А. Цыбатова [Цыбатов, 2016]. Исследо- 
ватели не только раскрывают программы регионального стратегического планирования, но и вносят коррективы в сам процесс планирования и программного развития территорий.

Пока во многих регионах отсутствуют ожидаемые прогнозы от программ социально-экономического развития. По мнению В.В. Климанова и К.В. Будаевой, необходимо своевременно вносить корректировки в региональные нормативно-правовые акты, а также прогнозировать получение ожидаемых результатов [Климанов, Будаева, 2016]. На региональном уровне социально-экономического развития к основным принципам стратегического планирования относятся полномочия пространственно территориального развития, что позволяет сохранять целостность, сбалансированность, согласованность и разграничение полномочий [Митрофанова, 2016].

Процесс обсуждения стратегий программ стратегического планирования с общественностью, наукой, бизнесом, властью (региональными представителями) систематизирует процессы интеграции регионов и их муниципальных образований и городских округов [Жихаревич, 2018; Лебедева, Жихаревич, 2018].

Во время присоединения крымского региона к Российской Федерации его экономика перешла в стадию планирования и прогнозирования и продолжила развиваться благодаря финансовым ресурсам в виде инвестиций [Дудин и др., 2017].

Принципы и факторы планирования сложно отделять от факторов влияния, власти (заказчика), общества, модели или технологии, показателей социально-экономического развития, а также определять полезность стратегического планирования [Ильина и др., 2016; Маркварт, 2017$].$

Последнее является основой социально-экономического развития на долгосрочную перспективу, определяя рост экономики по отраслям, эффективность использования инвестиционных ресурсов, а также дальнейшие направления развития страны.

\section{Характерные особенности региона: стратегическое планирование инвестиционной деятельности}

В начале 2014 г. произошло важное историческое событие для жителей Республики Крым (далее - региона): по итогам проведенного референдума 18 марта 2014 г. в Георгиевском зале Кремля был подписан договор о включении Крыма и г. Севастополя в состав Российской Феде- рации. Именно с этого исторического дня регион начал новую хозяйственную деятельность, которая берет свое начало с подготовки программ стратегического планирования, опираясь на Федеральный закон № 172-Ф3 «О стратегическом планировании в Российской Федерации».

В регионе приняли Закон «О стратегии социально-экономического развития Республики Крым до 2030 года». На его основании была разработана «Стратегия социально-экономического развития Республики Крым до 2030 г.». Следующим этапом стратегирования стала разработка стратегий развития муниципальных районов и городских округов до 2030 года.

В 2017 г. Советом министров Республики Крым в распоряжении от 30.01.2017 № 73-p «О создании в Республике Крым центра кластерного развития» началась реализация следующего этапа планирования для регионального развития. При рассматрении вопросов планирования кластерного развития в основе этих программ было заложено долгосрочное социально-экономическое развитие регионов, создание конкурентной экономики знаний и высоких технологий [Борщ, Герасимова, 2018]. Создаются кластерные инициативы и разрабатываются семь кластеров долгосрочных периодов развития, а именно: IT-технологий; туристический; медико-биологический; АПК; биотехнологический; инновационный; судостроительный. Разработка программных кластеров проходит процессы обсуждения с представителями малого и среднего бизнеса, населением, научными коллективами, с привлечением стейкхолдеров. Это, а также проведение полевых исследований и опрос разных слоев населения при проведении стратегических сессий может при обработке данных определить процесс развития и способствать выработке инструментов влияния для реализации программы [Тажитдинов, 2013; Garcia, Mendoza, Sanchez, 2017]. Во время этого процесса нарабатываются полномочия участников, уточняется иерархия и содержание кластеров, определяются основные программы, подпрограммы, предлагаются инструменты и механизмы реализации кластеров.

В рамках реализации стратегии развития региона до 2030 г. для инвестиционной деятельности и создания привлекательного инвестиционного климата была создана свободная экономическая зона. Ее преимущество заключается в освобождении от уплаты налога на имущество организаций на 10 лет, пониженных тарифах на страховые взносы (7,6 \% в совокупности), сво- 
бодной таможенной зоне, освобождении от уплаты земельного налога организациями на 3 года, пониженных ставках налога на прибыль (от 2 \%), ускоренной амортизации (с коэффициентом до 2) [О социально-экономическом положении ..., 2018]. Согласно ежегодному рейтингу инвестиционной привлекательности регионов России, составленным Национальным рейтинговым агентством, в 2017 г. Республика Крым и г. Севастополь вошли в категорию умеренной инвестиционной привлекательности (IC9). Отметим, что в рейтинге данные регионы участвовали впервые [Итоги $\mathrm{V}$ ежегодного рейтинга ..., 2017].

В регионе действует Порядок рассмотрения обращений инвесторов и заключения соглашений о реализации инвестиционных проектов на территории Республики Крым, утвержденный постановлением Совета министров Республики Крым от 07.10.2014 № 368, который предусматривает 30-дневную процедуру рассмотрения обращения инвестора и заключения с ним инвестиционного соглашения. Наиболее привлекательными для инвесторов являются: курортно-туристическая и топливно-энергетическая сферы, сельское хозяйство, строительство и промышленность.

\section{Формирование инвестиционного климата}

Данное исследование позволяет указывать на расширение географии инвесторов в регионе. Сегодня на территории Крыма зарегистрировано порядка 2930 юридических лиц, учредителями которых являются иностранные организации (595) и физические лица (2 335) из 33 стран: Украины, Кипра, Виргинских островов, Великобритании, Австрии, Белиза, Панамы, Сейшельских островов, Турции и др.

Работа с инвесторами, реализующими проекты на территории региона, выстраивается с применением системы проектного управления, что позволяет сократить сроки согласования инвестиционных проектов, упростить процедуру контроля их реализации, а также предоставляет возможность инвестору отслеживать процесс согласования проекта в «личном кабинете».

На официальном сайте Правительства Республики Крым развернуто и успешно функционирует автоматизированная информационная система управления проектной деятельностью исполнительных органов государственной власти Республики Крым. Она разработана и утверждена постановлением Совета министров Республики Крым от 25.07.2017 № 371 «Об утверждении По- ложения о системе управления проектной деятельностью в исполнительных органах государственной власти Республики Крым и органах местного самоуправления муниципальных образований в Республике Крым». Эта система - основная нормативная база, регламентирующая проектную деятельность на территории Республики Крым.

В 2017 г. созданы и функционируют Проектный комитет Республики Крым, Центральный проектный офис, в исполнительных органах государственной власти и муниципалитетах созданы функциональные и муниципальные проектные офисы соответственно. Разработана система мотивации участников проектной деятельности, которая утверждена постановлением Совета министров Республики Крым от 05.12.2017 № 654 «Об утверждении Положения о мотивации участников проектной деятельности в исполнительных органах государственной власти Республики Крым».

По результатам оценки внедрения проектного управления регион занял III призовое место в ежегодном конкурсе профессионального управления проектной деятельностью в государственном секторе «Проектный Олимп», проводимом Аналитическим центром при Правительстве Российской Федерации.

На базе ГАУ Республики Крым «Центр инвестиций и регионального развития» зарегистрирован Региональный центр Сертификации; ведутся работы по организации обучения и сертификации, а именно: составлен график обучения, ведутся работы по формированию списков будущих участников сертификационных испытаний.

\section{Регион с повышенным инвестиционным запросом}

Крым сегодня является территорией с повышенным инвестиционным запросом, для этого на государственном уровне создаются благоприятные условия инвестирования и тем самым повышается влияние положительных факторов по привлечению инвестиций. Чем больший объем инвестиций удасться привлечен в регион, тем меньше будет влияние деструктивных факторов (см. табл. 1).

Применение индикативного метода для разработки методики оценки инвестиций в регион предполагает последовательное выполнение следующих процедур: формирование системы инвестиционных показателей, обоснование их пороговых значений, установление правил расчета инвестиционного показателя. 
При выполнении первой из них необходимо соблюдать определенные требования, предъявляемые к системе инвестиционных индикаторов:

1. Инвестиционные показатели в процессе анализа должны давать полную и всестороннюю характеристику состояния и функционирования объекта наблюдения региональных инвестиций.

2. Показатели должны отвечать требованиям системности, показывая взаимосвязи и взаимозависимости, при анализе мы получаем их объективную оценку.

3. Инвестиционные показатели количественно измеримы, показывают уровень плановых показателей и с их помощью выявляются негативные тенденции и устанавливаются причины для принятия необходимых решений.

4. Показатели должны обладать высокой чувствительностью к негативным явлениям и процессам, способным причинить ущерб объекту наблюдения. Только в этом случае инвестиционные индикаторы могут выполнять свое главное предназначение - своевременно сигнализировать о возникновении отклонений от прогнозных показателей.
5. Инвестиционные показатели должны быть совместимы с системой показателей, применяемых в статистическом учете [Шашко, 2010].

Для определения инвестиционных показателей в регионе используем три группы показателей (рис. 1). Первую характеризует инвестиционный климат региона, к которому относятся: валовой региональный продукт ВРП; объем валового регионального продукта на душу населения; отношение объема государственного долга к ВРП; число преступлений на 100 тыс. чел. населения.

Вторая группа показателей - инвестиционный ресурсный потенциал: инвестиции в основной капитал; инвестиции в основной капитал к ВРП, \%; объем инвестиций в основной капитал на душу населения, руб.; коэффициент инвестирования за счет собственных средств, \%; доля инвестиций в основной капитал иностранной формы собственности, \%.

К третьей группе показателей эффективности использования инвестиционных ресурсов относят ВРП. Для того, чтобы оценить достаточность инвестиций в основной капитал, на региональном уровне рассчитывают долю инвестиций в основной капитал в ВРП, и этот показатель дол-

Таблица 1

\section{Факторы, влияющие на инвестиционную привлекательность Республики Крым}

\begin{tabular}{|l|l|}
\hline \multicolumn{1}{|c|}{ Положительные факторы } & \multicolumn{1}{|c|}{ Деструктивные факторы } \\
\hline - экономико-географическое положение с нали- & - недостаток водных ресурсов; \\
чием выхода к морям; & - введение экономических санкций; \\
- введение свободной экономической зоны; & - низкий уровень инвестиционной активности \\
- наличие агроклиматических ресурсов; & крымских предприятий; \\
- наличие курортных, туристических и рекреа- & - высокая стоимость привлеченного капитала; \\
ционных ресурсов; & - высокий износ основных фондов; \\
- наличие агропромышленности, судостроения, & - масштабная теневая экономика; \\
химической отрасли; & - сезонность работы предприятий туриндустрии \\
- наличие залежей горно-химического сырья, \\
природного газа, строительных материалов; \\
- спокойная обстановка в разнонациональном \\
социуме
\end{tabular}

Примечание. Составлено авторами.

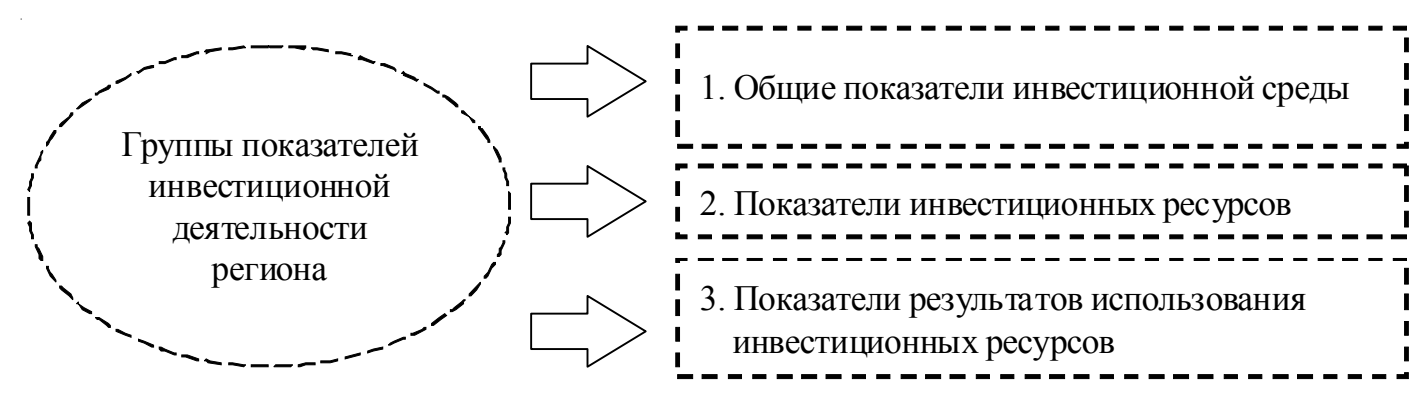

Рис. 1. Группы показателей оценки инвестиционной деятельности в регионе

Примечание. Составлено авторами. 
жен быть не менее 25 \% [Инвестиции ..., 2018; О социально-экономическом положении ... , 2018; Шашко, 2010]. Коэффициент инвестирования за счет собственных средств отражает собственный инвестиционный потенциал региона.

Динамика инвестиций в основной капитал по годам исследования является одним из главных показателей инвестиционной политики, так как увеличение объема инвестиций свидетельствует об улучшении инвестиционного климата в регионе. Инвестиции в основной капитал направляются, в том числе на поддержание нормального состояния основных фондов.

Перечисленные показатели не являются исчерпывающим перечнем. Однако имеющиеся данные показывают, что таких количественных показателей достаточно для оценки общего уровня инвестиционной безопасности и выявления угроз ее снижения. Условный показатель, определяющий оценку состояния основных фондов региона, несущий аналитическое значение, определяется коэффициентом износа основных средств.

\section{Расчет интегральных показателей: структура инвестиций в основной капитал региона}

Для расчета интегрального показателя инвестиционной безопасности региона все показатели инвестиционной безопасности необходимо привести в сопоставимый вид. Для этого необходимо сопоставить полученное числовое значение каждого показателя с его нормативным значением, то есть провести стандартизацию. Приведение показателей инвестиционной безопасности региона осуществляется в следующей последовательности:
1. Для каждого $i$-го показателя фиксируется его нормативное значение $a_{i}{ }^{\text {нл }}$.

2. Вычисляется степень отклонения показателя инвестиционной деятельности от нормативного (среднерегионального) значения:

$\mathrm{x}_{\mathrm{ij}}=\frac{\mathrm{a}_{\mathrm{ij}}}{\mathrm{a}_{\mathrm{ij}}}$, если направление оптимизации показателя $\Rightarrow \max$;

$\mathrm{x}_{\mathrm{ij}}=\frac{\mathrm{a}_{\mathrm{ij}}^{\text {нл }}}{\mathrm{a}_{\mathrm{ij}}}$, если направление оптимизации показателя $\Rightarrow \min$.

Следующим этапом оценки инвестиционной деятельности региона является расчет интегральных показателей по каждой из групп показателей, а также расчет общего интегрального показателя инвестиционной деятельности. Групповые интегральные показатели рассчитываются путем сложения всех показателей группы. Общий интегральный показатель представляет собой сумму всех значений групповых интегральных показателей. В таблицах 2 и 3 отражены основные показатели по каждой из групп.

В регионе растет экономический потенциал, так как в последние годы наблюдается увеличение ВРП (см. рис. 3). В 2017 г. экономика Крыма выросла на 10 \% (рекордные темпы роста за последнее десятилетие), вследствие чего увеличивается объем инвестиций в основной капитал.

Согласно результатам проведенного анализа показателей инвестиционной деятельности в регионе, можно сделать следующие выводы: увеличиваются инвестиции в основной капитал, однако их доли в ВРП недостаточно для полноценного развития экономики; происходит снижение инвестиционного потенциала за счет собственных средств; региону недостаточно объема иностранных инвестиций; наблюдается критический

Таблица 2

\section{Структура инвестиций в основной капитал в Республике Крым, млрд руб.}

\begin{tabular}{|l|c|c|c|c|c|}
\hline \multicolumn{1}{|c|}{ Показатели } & 2014 & 2015 & 2016 & 2017 & 2018 \\
\hline Инвестиции в основной капитал, всего & 26,5 & 47,6 & 74,8 & 195,4 & 230,5 \\
\hline \multicolumn{7}{|c|}{ Структура инвестиций } \\
\hline Собственные средства & 5,5 & 11,5 & 15,3 & 15,5 & - \\
\hline Средства из Федерального бюджета & 6,7 & 14,7 & 30,6 & 93,8 & - \\
\hline Структура инвестиций в основной капитал в: & 27,0 & 47,5 & 74,8 & 109,1 & - \\
жилье; & 7,6 & 5,1 & 6,6 & 1,5 & - \\
здания и сооружения; & 10,2 & 11,8 & 33,5 & 86,9 & - \\
машины и оборудование, транспортные средства, & & & & & - \\
инвентарь; & 7,4 & 21,2 & 32,2 & 18,9 & - \\
прочие & 1,3 & 9,4 & 2,5 & 1,8 & - \\
\hline
\end{tabular}

Примечание. Составлено авторами по [Инвестиции ... , 2018] 


\section{S.V. Gerasimova, M.L. Borshch. Assessment of Investment Resources of the Region in the Strategic Context}

недостаток инвестиций в научные исследования; происходит замедление процессов наращивания мощностей и расширения производства, так как уменьшились коэффициенты обновления и выбытия основных средств; основные фонды региона изношены и требуют обновления.

\section{Оценка инвестиционной деятельности в регионе: индикативный подход}

Применение индикативного подхода предполагает расчет интегрального показателя инвестиционной деятельности. Для этого приведем показатели, влияющие на инвестиционную деятельность в регионе в сопоставимый ряд посредством расчета отклонений их значений от нормативных. Произведем расчет совокупного показателя инвестиционной деятельности каждой группы показателей, а затем интегральный показатель, характеризующий инвестиционную деятельность региона (табл. 4).

Норматив первой группы показателей равен 4, так как в группе четыре показателя и положительное минимальное значение каждого из них должно быть равно 1. Уменьшение совокупного показателя инвестиционной среды обуслов-

Таблица 3

Анализ инвестиционной деятельности в Республике Крым по группам показателей

\begin{tabular}{|c|c|c|c|c|}
\hline Показатели & 2014 & 2015 & 2016 & 2017 \\
\hline Динамика ВРП региона, млн руб. & 190000 & 260000 & 311000 & 315000 \\
\hline Динамика ВРП на душу населения, тыс. руб. & 100,0 & 140,0 & 165,0 & 170,0 \\
\hline Динамика государственного долга к ВРП в \% соотношении & 0,4 & 0,2 & 1,65 & 1,4 \\
\hline Норматив & 0,8 & 0,8 & 0,8 & 0,8 \\
\hline Динамика числа преступлений на 100 тыс. чел. & 910 & 1405 & 1203 & 1090 \\
\hline Динамка объема инвестиций в основной капитал на душу населения, тыс. руб. & 17,0 & 25,0 & 40,0 & 100,0 \\
\hline Коэффициент инвестиций за счет собственных средств, в \% соотношении & 45 & 47,5 & 32,0 & 14,0 \\
\hline Норматив & 37 & 37 & 37 & 37 \\
\hline Динамика внутренних затрат на научные исследования к ВРП, в \% & 0,25 & 0,4 & 0,47 & 0,51 \\
\hline Коэффициент обновления основных фондов, в \% & 34,0 & 13,8 & 5 & - \\
\hline Динамика выбытия основных фондов в \% соотношении & 1,2 & 3,85 & 2,9 & - \\
\hline
\end{tabular}

Примечание. Составлено авторами на основании данных [Инвестиции ..., 2018].

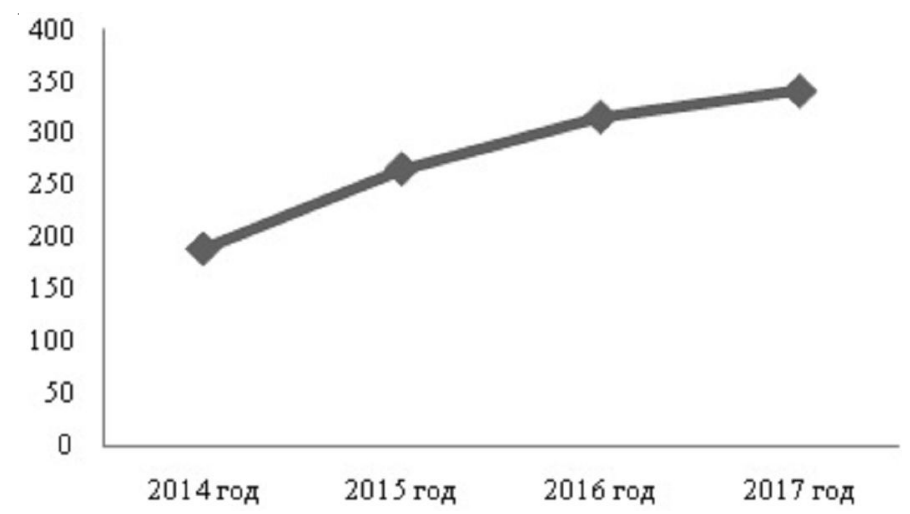

Рис. 3. Динамика ВРП Республики Крым в 2014-2017 гг., млрд руб.

Примечание. Составлено авторами по [Республика Крым в цифрах ... , 2016].

Расчет совокупного показателя, характеризующего инвестиционную среду в Республике Крым за 2014-2016 гг.

\begin{tabular}{|c|l|c|c|c|}
\hline$№$ п/п & \multicolumn{1}{|c|}{ Наименование показателя } & 2014 г. & 2015 г. & 2016 г. \\
\hline 1. & ВРП & 0,7368 & 1,0345 & 1,2287 \\
\hline 2. & Объем валового регионального продукта на душу населения & 0,7409 & 1,0341 & 1,2250 \\
\hline 3. & Отношение объема государственного долга к ВРП & 2,7754 & 4,5491 & 0,4132 \\
\hline 4. & Число преступлений, на 100 тыс. чел. населения & 1,2690 & 0,8366 & 0,9835 \\
\hline Совокупный показатель & 5,5221 & 7,4543 & 3,8505 \\
\hline
\end{tabular}

Примечание. Рассчитано авторами. 
лено значительным увеличением в декабре 2016 г. государственного долга Республики Крым в абсолютной величине, вследствие чего значительно уменьшился приведенный показатель. Таким образом, инвестиционная среда в 2016 г. ухудшилась по причине резкого увеличения государственного долга региона (табл. 5).

В 2016 г. в Республике Крым зафиксировано недостаточное соотношение инвестиций в основной капитал по отношению к ВРП, а также объем вложения иностранных инвестиций в основной капитал. Наиболее негативное влияние на формирование совокупного показателя инвестиционных ресурсов оказало изменение показателя доли инвестиций в основной капитал иностранной формы собственности. Привлечение иностранных инвестиций в экономику региона позволит коренным образом изменить ситуацию в этой группе показателей (табл. 6).

Совокупный показатель эффективности использования инвестиционных ресурсов составил приведенный показатель «Внутренние затраты на научные исследования к ВРП». Его малые значения свидетельствуют о недостаточном уровне финансирования научных исследований на предприятиях региона.
Рост приведенного показателя «Доля новых основных средств в общем поступлении основных средств» объясняется тем, что в структуре поступления основных средств все больше внимания стало уделяться новым основным средствам.

Динамика показателя коэффициента обновления основных фондов свидетельствует об общем уменьшении поступления основных фондов на крымских предприятиях. По коэффициенту износа наблюдается высокий уровень изношенности основных фондов.

Доля инвестиций в активную часть основных средств в общей сумме увеличилась за анализируемый период, что свидетельствует о достаточном объеме инвестиций в активную часть основных средств в общей их сумме.

Таким образом, расчет совокупного показателя результатов использования инвестиций в регионе показал разные значения. Особо следует обратить внимание на низкие внутренние затраты на научные исследования, уменьшение коэффициента обновления основных фондов и достаточно высокий уровень изношенности основных средств. Корректировка этих групп показателей позволит эффективно использовать инвестиционные ресурсы региона.

Таблица 5

\section{Расчет совокупного показателя, характеризующего динамику инвестиционных ресурсов в Республике Крым за 2014-2016 гг.}

\begin{tabular}{|c|l|c|c|c|}
\hline$№$ п/п & \multicolumn{1}{|c|}{ Наименование показателя } & 2014 г. & 2015 г. & 2016 г. \\
\hline 1. & Инвестиции в основной капитал & 0,5331 & 0,9592 & 1,5077 \\
\hline 2. & Инвестиции в основной капитал к ВРП & 0,5584 & 0,7156 & 0,9470 \\
\hline 3. & Объем инвестиций в основной капитал на душу населения & 0,5364 & 0,9594 & 1,5041 \\
\hline 4. & Коэффициент инвестирования за счет собственных средств & 1,2189 & 1,2703 & 0,9027 \\
\hline 5. & $\begin{array}{l}\text { Доля инвестиций в основной капитал иностранной формы } \\
\text { собственности }\end{array}$ & 0,3605 & 0,1666 & 0,1719 \\
\hline \multicolumn{2}{|l|}{ Совокупный показатель } & 3,2073 & 4,0711 & 5,0335 \\
\hline
\end{tabular}

Примечание. Рассчитано авторами.

Таблицча 6

\section{Расчет совокупного показателя эффективности использования инвестиционных ресурсов} в регионе за 2014-2016 гг.

\begin{tabular}{|c|l|c|c|c|}
\hline № п/п & \multicolumn{1}{|c|}{ Наименование показателя } & 2014 г. & 2015 г. & 2016 г. \\
\hline 1. & Внугренние затраты на научные исследования к ВРП & 0,1351 & 0,2323 & 0,2233 \\
\hline 2. & Ввод в действие новых основных средств & 0,3611 & 0,8029 & 1,8360 \\
\hline 3. & Доля ввода новых ОС в общем поступлении ОС & 0,1338 & 0,4558 & 2,4103 \\
\hline 4. & Коэффициент обновления основных фондов & 1,8994 & 0,7522 & 0,3217 \\
\hline 5. & Коэффициент выбытия основных фондов & 3,8168 & 1,3123 & 1,7007 \\
\hline 6. & Коэффициент износа основных фондов & 0,5674 & 0,5594 & 0,5731 \\
\hline 7. & Доля инвестиций в активную часть ОС в общей сумме & 0,7240 & 1,1574 & 1,1185 \\
\hline Совокупный показатель & 7,6376 & 5,2723 & 8,1836 \\
\hline
\end{tabular}

Примечание. Рассчитано авторами. 
Стоит отметить, что в каждом из периодов исследования наблюдаются разные проблемы. Так, в 2014 г. основной проблемой региона стала недостаточность инвестиционных ресурсов, в 2015 г. - низкий показатель результатов использования инвестиционных ресурсов, а в 2016 г. неудовлетворительным был совокупный показатель инвестиционной среды.

По данным исследования инвестиционная деятельность в регионе за период 2014-2016 гг. находилась на минимально необходимом уровне, имея положительную динамику, что свидетельствует о повышении инвестиционной активности в регионе.

Имея статистические данные за 2017 г. только по двум группам показателей, можем рассчитать интегральный показатель инвестиционной деятельности за 2014-2017 годы (табл. 7).

Практически все значения показателей инвестиционной деятельности первой группы за 2014-2017 гг., кроме приведенных показателей ВРП и подушевого ВРП, поднялись выше нормативного значения. Низкие значения показателя «Отношения объема государственного долга к ВРП» обусловлены большими суммами государственного долга Республики Крым в 2016-2017 гг., вследствие чего совокупный показатель инвестиционных ресурсов очень низкий. Положительная динамика совокупного показателя инвестиционной среды в 2017 г. произошла вследствие уменьшения отношения объема государственного долга к ВРП и сни- жения количества преступлений на 100 тыс. чел. населения в регионе.

В 2017 г. наблюдается увеличение показателей инвестиций в основной капитал, инвестиций в основной капитал к ВРП, а также инвестиций в основной капитал на душу населения. Это связано с тем, что в 2017 г. инвестиции в основной капитал увеличились более чем в 2,5 раза. Снизился коэффициент инвестирования за счет собственных средств, также произошло снижение доли инвестиций в основной капитал иностранной формы собственности. Следует отметить, что совокупный показатель динамики инвестиционных ресурсов постоянно увеличивался, что объясняется, прежде всего, постоянным увеличением объемов инвестиций в основной капитал в регион.

\section{Заключение}

Рассматривая инвестиции с позиции макрои микроэкономики, можно убедиться в том, что они формируют производственный потенциал, обладающий новыми научно-технологическими свойствами. Эффективное его использование в воспроизводственных процессах повышает их конкурентные преимущества. Достигаются такие результаты через систему стратегического планирования, разработку и консолидацию всех процессов в инвестиционной деятельности.

Данное исследование углубляет понимание достижения результатов с применением

Таблица 7

Приведенные показатели инвестиционной деятельности Региона за 2014-2017 гг.

\begin{tabular}{|c|c|c|c|c|c|}
\hline № & Показатели & 2014 г. & 2015 г. & 2016 г. & 2017 г. \\
\hline \multicolumn{6}{|c|}{ Показатели инвестициионной среды } \\
\hline 1 & 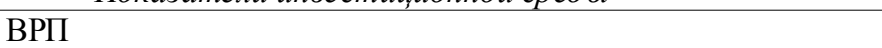 & 0,7368 & 1,0345 & 1,2287 & 1,1821 \\
\hline 2 & Объем валового регионального продукта на душу населения & 0,7409 & 1,0341 & 1,2250 & 1,1783 \\
\hline 3 & Отношение объема государственного долга к ВРП & 2,7754 & 4,5491 & 0,4132 & 0,6399 \\
\hline \multirow[t]{2}{*}{4} & Число преступлений на 100.0 тыс. человек населения & 1,2690 & 0,8366 & 0,9835 & 1,0581 \\
\hline & Совокупный показатель инвестиционной среды & 5,5221 & 7,4543 & 3,8504 & 4,0584 \\
\hline \multicolumn{6}{|c|}{ Показатели инвестиционных ресурсов } \\
\hline 1 & Инвестиции в основной капитал & 0,5331 & 0,9592 & 1,5077 & 2,2705 \\
\hline 2 & Инвестиции в основной капитал к ВРП & 0,5584 & 0,7156 & 0,9470 & 2,4154 \\
\hline 3 & Объем инвестиций в основной капитал на душу населения & 0,5364 & 0,9594 & 1,5041 & 2,2667 \\
\hline 4 & Коэффициент инвестирования засчет собственных средств & 1,2189 & 1,2703 & 0,9027 & 0,3838 \\
\hline 5 & $\begin{array}{l}\text { Доля инвестиций в основной капитал иностранной формы } \\
\text { собственности }\end{array}$ & 0,3605 & 0,1666 & 0,1719 & 0,0600 \\
\hline \multicolumn{2}{|r|}{ Совокупный показатель динамики инвестиционных ресурсов } & 3,2073 & 4,0711 & 5,0334 & 7,3964 \\
\hline \multicolumn{2}{|r|}{$\begin{array}{l}\text { Интегральный показатель инвестиционной безопасности Респуб- } \\
\text { лики Крым }\end{array}$} & 8,73 & 11,53 & 8,88 & 11,45 \\
\hline
\end{tabular}

Примечание. Рассчитано авторами. 
стратегического планирования и прогнозирования для эффективного использования ресурсного потенциала, готовности государства, бизнеса и общества выстраивать алгоритм доверия между ними, эффективно использовать ресурсный потенциал данного региона, для обеспечения непрерывного воспроизводственного процесса, обеспечивая прогрессивное социально-экономическое развитие.

Результаты анализа и оценки интегральных показателей инвестиционной деятельности показали, что в регионе необходимо развивать инвестиционную инфраструктуру, усовершенствовать институциональные механизмы, влияющие на формирование инвестиционного климата с целью устранения диспропорций на ранних стадиях их проявления, и вносить нужные коррективы.

Применение оценки интегральных показателей в инвестиционной деятельности позволит эффективно распределять инвестиционные ресурсы, выделяемые из государственного бюджета на развитие регионов, для поддержания пространственного развития регионов, формируя новое региональное экономическое пространство с целью получения от регионов синергетического эффекта.

\section{СПИСОК ЛИТЕРАТУРЫ}

Анимица Е. Г., 2005. Стратегическое планирование развития территории: сущность, основные принципы, проблемы // Известия Уральского государственного экономического университета. № 12 . C. 87-95.

Борщ Л. М., Герасимова С. В., 2018. Пространственная модель инновационного технологического регионального развития // Научно-технические ведомости СПбГПУ. Экономические науки. Т.11, № 4. С. 185-199.

Дудин М. Н., Лясников Н. В., Буркальцева Д. Д., Лисицкий А. М., 2017. Актуальные вопросы инновационного развития Республики Крым: оценка инвестиционного потенциала на современном этапе // Актуальные проблемы социально-экономического развития России. № 1. С. 19-33.

Жихаревич Б. С., 2018. О результативности стратегического планирования // Региональная экономика. Юг России. № 1 (19). С. 16-22. DOI: https:// doi.org/10.15688/re.volsu.2018.1.2.

Жихаревич Б. С., Прибышин Т. К., 2013. Распространение практики стратегического планирования в городах России: 1997-2013 гг. // Известия Русского географического общества. Т. 145, № 6. С. 1-10.

Ильина И. И., Плисецкий Е. Е., Копыченко Г. С., Рыбина Е. Г., 2016. Оценка качества разработки регио- нальных стратегий развития в России // Региональная экономика: теория и практика. № 4 (427). C. $178-196$.

Инвестиции, 2018 // Официальный сайт Управления Федеральной службы государственной статистики по Республике Крым и г. Севастополю. URL: http://crimea.gks.ru/wps/wcm/connect/rosstat_ts/ crimea/ru/statistics/stat_Crimea/enterprises/ investment/.

Итоги V ежегодного рейтинга инвестиционной привлекательности регионов России, URL: http:// lenoblinvest.ru/images/National_Rating _ Agency_2017.pdf.

Каранина Е. В., 2016. Финансовая безопасность (на уровне государства, региона, организации, личности) : монография. Киров : ВятГУ. 240 с.

Климанов В. В., Будаева К. В., 2016. Региональное стратегирование: анализ итогов 2015 года // Бюджет. Июнь (№ 6). С. 90-94.

Лебедева Н. А., Жихаревич Б. С., 2018. Стратеги о стратегическом планировании // Региональная экономика. Юг России. 2018. № 1 (19). С. 6-15. DOI: https://doi.org/10.15688/re.volsu.2018.1.1.

Маркварт Э., 2017. Участие жителей в стратегическом планировании - обременительная обязанность или нераскрытый потенциал? // Вестник экспертного совета. № 2 (9). С. 26-32.

Митрофанова И. В., 2016. Модернизация региональной системы стратегического планирования: проблемы и решения // Общество: политика, экономика, право. № 5. С. 56-62.

О социально-экономическом положении и инвестиционной привлекательности Республики Крым и города Севастополя, 2018. URL: http://www.mid.ru/ vnesneekonomiceskie-svazi-sub-ektov-rossijskojfederacii/-/asset_publisher/ykggrK2nCl8c/content/ id/3279381.

Республика Крым в цифрах, 2016 : крат. стат. сб., 2017. Симферополь : Крымстат. 143 с.

Селиверстов В. Е., 2013. Региональное стратегическое планирование: от методологии к практике. Новосибирск : ИЭОПП СО РАН. 436 с.

Тажитдинов И. А., 2013. Применение стейкхолдерского подхода в стратегическом управлении развитием территорий // Экономика региона. № 2 . C. 17-27.

Финансы России, 2016 : стат. сб. М. : Росстат. 343 с.

Цыбатов В. А., 2016. Макроэкономическое моделирование, прогнозирование и планирование регионального развития : учеб. пособие. Самара : СГУ. $314 \mathrm{c}$.

Шашко А. А., 2010. Конкурентоспособность региона: сущность и управление // Новая экономика. № 1. С. $45-54$.

Швецов А. Н., Демьяненко А. Н., Украинский В. Н., 2016. Деструктивные стереотипы российского стратегического планирования и их возможные последствия для практики регионального страте- 
гирования (часть 1) // Регионалистика. Т. 3, № 3. C. 48-60.

Garcia. J., Mendoza J., Sanchez P., 2017. Innovation and Regional Development in Mexico, Innovacion Y Desarrollo Regional en Mexico // Revista Global de Hegocios. № 5 (7). P. 85-95.

\section{REFERENCES}

Animitsa E.G., 2005. Strategicheskoe planirovanie razvitiya territorii: sushchnost, osnovnye printsipy, problemy [Strategic Planning of the Development of the Territory: the Essence, Basic Principles, Problems]. Izvestiya Uralskogo gosudarstvennogo ekonomicheskogo universiteta [Journal of the Ural State University of Economics], no. 12, pp. 87-95.

Borshch L.M., Gerasimova S.V., 2018. Prostranstvennaya model innovatsionnogo tekhnologicheskogo regionalnogo razvitiya [Spatial Model of Innovative Technological Regional Development]. Nauchnotekhnicheskie vedomosti SPbGPU. Ekonomicheskie nauki, vol. 11, no. 4, pp. 185-199.

Dudin M.N., Lyasnikov N.V., Burkaltseva D.D., Lisitskiy A.M., 2017. Aktualnye voprosy innovatsionnogo razvitiya Respubliki Krym: otsenka investitsionnogo potentsiala na sovremennom etape [Current Issues of Innovative Development of the Republic of Crimea: Assessment of the Investment Potential at the Present Stage]. Aktualnye problemy sotsialno-ekonomicheskogo razvitiya Rossii, no 1, pp. 19-33.

Zhikharevich B.S., 2018. O rezultativnosti strategicheskogo planirovaniya [On the Effectiveness of Strategic Planning]. Regionalnaya ekonomika. Yug Rossii [Regional Economy. The South of Russia], no. 1 (19), pp. 16-22.DOI: https://doi.org/10.15688/re.volsu.2018.1.2

Zhikharevich B.S., Pribyshin T.K., 2013. Rasprostranenie praktiki strategicheskogo planirovaniya v gorodakh Rossii: 1997-2013 gg. [Spread of the Practice of Strategic Planning in the Cities of Russia: 19972013.]. Izvestiya Russkogo geograficheskogo obshchestva [Proceeding of the Russian Geographical Society], vol. 145, no. 6, pp. 1-10.

Ilyina I.I., Plisetskiy E.E., Kopychenko G.S., Rybina E.G., 2016. Otsenka kachestva razrabotki regionalnykh strategiy razvitiya v Rossii [Quality Assessment of the Development of Regional Development Strategies in Russia]. Regionalnaya ekonomika: teoriya i praktika [Regional Economics: Theory and Practice], no. 4 (427), pp. 178-196.

Investitsii, 2018. Ofitsialniy sait Upravleniya Federalnoy sluzhby gosudarstvennoy statistiki po Respublike Krym ig. Sevastopolyu [Investments. Official Website of the Office of the Federal State Statistics Service in the Republic of Crimea and the City of Sevastopol]. URL: http:/crimea.gks.ru/wps/wcm/connect/rosstat_ts/ crimea/ru/statistics/stat_Crimea/enterprises/ investment/.
Itogi $V$ ezhegodnogo reytinga investitsionnoy privlekatelnosti regionov Rossii, 2017 [Results of the $5^{\text {th }}$ Annual Rating of Investment Attractiveness of Russian Regions, 2017]. URL: http://lenoblinvest.ru/ images/National_Rating_Agency_2017.pdf.

Karanina E.V., 2016. Finansovaya bezopasnost (na urovne gosudarstva, regiona, organizatsii, lichnosti) [Financial Security (at the Level of the State, Region, Organization, Individual)]. Kirov, Vyatka State University Publ. 240 p.

Klimanov V.V., Budaeva KV., 2016. Regionalnoe strategirovanie: analiz itogov 2015 goda [Regional Strategizing: an Analysis of the Results of 2015]. Byudzhet, no. 6, pp. 90-94.

Lebedeva N.A., Zhikharevich B.S., 2018. Strategi o strategicheskom planirovanii [Strategists on Strategic Planning]. Regionalnaya ekonomika. Yug Rossii [Regional Economy. The South of Russia], no. 1 (19), pp. 6-15. DOI: https://doi.org/10.15688/ re.volsu.2018.1.1

Markvart E., 2017. Uchastie zhiteley v strategicheskom planirovanii - obremenitelnaya obyazannost ili neraskrytiy potentsial? [Residents Participation in Strategic Planning - Burdensome Duty or Untapped Potential?]. Vestnik ekspertnogo soveta [Expert Council Bulletin], no. 2 (9), pp. 26-32.

Mitrofanova I.V., 2016. Modernizatsiya regionalnoy sistemy strategicheskogo planirovaniya: problemy i resheniya [Modernization of the Regional Strategic Planning System: Problems and Solutions]. Obshchestvo: politika, ekonomika, pravo [Society: Politics, Economics, Law], no. 5, pp. 56-62.

O sotsialno-ekonomicheskom polozhenii i investitsionnoy privlekatelnosti Respubliki Krym i goroda Sevastopolya, 2018 [On the Socio-Economic Situation and Investment Attractiveness of the Republic of Crimea and the City of Sevastopol, 2018]. URL: http:/ /www.mid.ru/vnesneekonomiceskie-svazi-sub-ektovrossijskoj-federacii/-/asset_publisher/ykggrK2nCl8c/ content/id/3279381.

Respublika Krym v tsifrakh: kratkiy statisticheskiy sbornik, 2016 [Republic ofCrimea in Numbers: Short Statistical Compilation, 2016]. Simferopol, Krymstat Publ. 143 p.

Seliverstov V.E., 2013. Regionalnoe strategicheskoe planirovanie: ot metodologii k praktike [Regional Strategic Planning: from Methodology to Practice]. Novosibirsk, SB RAS Publ. 436 p.

Tazhitdinov I.A., 2013. Primenenie steykkholderskogo podkhoda $v$ strategicheskom upravlenii razvitiem territorii [Application of a Stakeholder Approach in the Strategic Management of the Development of Territories]. Ekonomika regiona [Economy of Region], no. 2, pp. 17-27.

Finansy Rossii: statisticheskiy sbornik, 2016. [Finance of Russia: Statistical Compilation, 2016]. Moscow, Rosstat Publ. 343 p.

Tsybatov V.A., 2016. Makroekonomicheskoe modelirovanie, prognozirovanie $i$ planirovanie 
regionalnogo razvitiya: uchebnoe posobie [Macroeconomic Modeling, Forecasting and Regional Development Planning: Textbook]. Samara, Samara State University Publ. 314 p.

Shashko A.A., 2010. Konkurentosposobnost regiona: sushchnost i upravlenie [Competitiveness of the Region: the Nature and Management]. Novaya ekonomika [New Economy], no. 1, pp. 45-54.

Shvetsov A.N., Demyanenko A.N., Ukrainskiy V.N., 2016. Destruktivnye stereotipy rossiyskogo strategicheskogo planirovaniya i ikh vozmozhnye posledstviya dlya praktiki regionalnogo strategirovaniya (chast 1) [Destructive Stereotypes of Russian Strategic Planning and Their Possible Consequences for the Practice of Regional Strategizing (Part 1)]. Regionalistika, vol. 3, no. 3, pp. 48-60.

Garcia J., Mendoza J., Sanchez P., 2017. Innovation and Regional Development in Mexico, Innovacion Y Desarrollo Regional en Mexico. Revista Global de Hegocios, no. 5 (7), pp. 85-95.

\section{Information about the Authors}

Svetlana V. Gerasimova, Doctor of Sciences (Economics), Professor, Department of Business Informatics and Mathematical Modeling, Institute of Economics and Management, Crimean Federal University named after V.I. Vernadsky, Sevastopolskaya St., 21/4, 295015 Simferopol, Russian Federation, svetlana-gerasimova-68@mail.ru, http://orcid.org/0000-0002-7077-6352

Lyudmila M. Borshch, Doctor of Sciences (Economics), Professor, Department of Business Finance and Insurance, Institute of Economics and Management, Crimean Federal University named after V.I. Vernadsky, Sevastopolskaya St., 21/4, 295015 Simferopol, Russian Federation, 1-borsh49@mail.ru, http://orcid.org/00000001-7729-3022

\section{Информация об авторах}

Светлана Васильевна Герасимова, доктор экономических наук, профессор, профессор кафедры бизнес-информатики и математического моделирования, Институт экономики и управления Крымского федерального университета им. В.И. Вернадского, ул. Севастопольская, 21/4, 295015 г. Симферополь, Российская Федерация, svetlana-gerasimova-68@mail.ru, http://orcid.org/0000-0002-7077-6352

Людмила Михайловна Борщ, доктор экономических науки, профессор, профессор кафедры финансов предприятий и страхования, Институт экономики и управления, Крымский федеральный университет им. В.И. Вернадского, ул. Севастопольская, 21/4, 295015 г. Симферополь, Российская Федерация, 1-borsh49@mail.ru, http://orcid.org/0000-0001-7729-3022 